\title{
Study on Tourists' Sensory Evaluation of the Destination and Its Influence on the Decision of Revisit
}

\author{
Yunli Shi \\ Feixian Campus, Linyi University, Linyi, Shandong, China \\ 15165519838@163.com
}

Keywords: Tourists; Sensory evaluation; Revisit decision; Structure model

\begin{abstract}
For tourists, their choice of destination often depends on their sensory evaluation of destination, which is the basic motive for the behavior of tourists and to a large extent, influences tourists' decision whether they revisit the place or not. The conclusion is drawn from the researches on the latest twenty years of relevant study. On the basis, the article analyzes the basic motives of tourists to revisit and the related influencing factors. At the same time, the paper makes a research on the practical application in marketing and tourism management of the tourists' destination awareness evaluation. Finally, combining with the researches of foreign tourists revisit behavior, some immature suggestions on future study is put forward. Hoping that this study can contribute to the understanding of tourists' revisit motives, and provide certain reference to the activities carried out in marketing and management.
\end{abstract}

\section{Introduction}

In general, to tourism management and marketing, a very important index to judge the satisfaction of the tourists to destination is the revisit rate, which is also an important decision-making basis for tourism destination marketing strategy. A revisit decision often involves a tourist's intrinsic demand and motivation, personal preference, and the recognition degree to tourism products as well. At present, many scholars are trying to study tourists' motives in order to obtain their decision-making process to revisit the destination and know the factors that effect their decision. From the current point of view, there are profound studies on this issue in foreign countries.

\section{The Influence of Tourists' Perception Evaluation on Revisit Decision}

According to consumer behavior model set up on the basis of Assails study (1998), the consumption process, along with the product or service, and perception evaluation has an important impact on re-purchase behavior. While for tourists, their destination evaluation belongs to consumer perception which influences tourists' revisit behavior significantly. Naturally, this issue has long been the research focus of scholars. Through the analysis of different tourist destination and the observation of variables, foreign scholars analyze various factors that have great effect on tourists' behavior, from which some of the main observation variables were found.

Evaluation of the Overall Satisfaction Level of Tourists to the Destination. For tourists, the overall satisfaction level of the destination directly affects tourists' revisit decision. Although the intention of the tourists to revisit basically is determined by the satisfaction degree of tourism destination, satisfaction degree is just a subjective evaluation, and it's not so easy to make a quantitative research on the subjective evaluation. Every time the tourist finishes his travel behavior, he will make a subjective judgment on whether his own spending is worth, or achieve his desired goals, or delight his own spirit. To this judgment is satisfaction. By comparing the perception of the products and its own expectations for each product, the consumers' satisfaction has been widely used in the framework design. Tourist satisfaction can greatly enhance tourists' revisit intention for tourism destination, so a large number of scholars have conducted in-depth researches for the structure of satisfaction, attempting to find out better quantitative method, through studying the connotation of satisfaction, so as to provide the basis for systematic research including Bigne et al2001; Bowen2001; Kozak2001a; Kozak\&Rimmington2000; Mazursky1989; Oh1999 and so on. 
To carry out a quantitative study on the satisfaction of tourists, generally a mode or scale that is consistent with the project is needed. Such a model can basically make comprehensive evaluation on tourist satisfaction no matter what kind of destination. Some foreign scholars believe that a tourist satisfaction is directly related to the evaluation of the nature of tourism destination, which includes natural landscape, cultural landscape and other aspects of the business environment. Baker Crompton (2000) has always been aware of the fact that the image study of the literature review will actually measure the perceived quality of the destination attribute (or expected performance). The destination is the combination of tourism facilities and services. It shows that, like other goods and services, the destination is composed of many destination attribute composite, which also determines that the specific situation of tourism has special attractive force to tourists. According to Binge et al (2001), the main result of the study is the satisfaction structure and the prerequisite that form satisfaction. And revisit tendency is considered as the result of tourist satisfaction model. $n$ these cases, it's better to say that revisit intention has long been regarded as a measure of satisfaction variables related to evaluation of the effectiveness of the associated standard rather than say that revisit intention is the dependent variables of the research questions. In other words, revisit intention is more the extension of satisfaction than the beginning of the decision-making process.

The excessive depletion of local natural resources in tourism destination will not only damage the living environment of local residents but also weaken tourists' revisit intention. Therefore, from this perspective, the development of tourism resources in tourism destination must be sustainable, never damage the state of nature excessively just for the sake of temporarily benefit. On the contrary, it's quite vital to preserve original ecological of the tourism destination as much as possible, reduce the speed of artificial development, and prevent excessive construction. And the main influence of the local community is the influence of the tourists through the social interaction. For example, tourists in the tourism destination can have more opportunities to contact with local residents, and in some special areas tourists can also accept a wide variety of cultural baptism. But the influence of the tourists on tourism destination can not cause too much disturb (Ross\&Wall1999). In addition, the interaction process can also make the tourists more cherish the local cultural resources, which can effectively enrich tourists' spiritual feeling, and effectively enhance the possibility to revisit the tourism destination.

After the questionnaire survey of more than 400 tourists was carried out in Singapore Changi International Airport, we found that tourists from different areas have different overall satisfactions for Singapore, and the factors affecting their evaluation are quite different. For example, Tourists from North America are more concerned about accommodation and food, while Asian and European tourists are more concerned about Singapore's attractions, and cultural factors have a greater impact on Oceania's tourists. From the comprehensive point of view, there is no one factor that would have the same effect for all the tourists. But it is worth mentioning that all tourists are willing to recommend their friends or relatives to come to Singapore again.

Perception of Tourism Destination Image. Through the retrieval of the foreign tourism literature, it is found that a tourist always has certain expectations, which may be the fundamental reason why they choose such a tourism destination. However, because the image is often multidimensional, it is a kind of accumulation and description of trust, thought and impression, thus it is a kind of subjective impression on the tourist destination.

In Queensland tourism industry in Australia, the tourist information center plays a very important role. The center provides very detailed information service in the tourism area, which encourages more tourists to stay in Queensland, and of course, the spending is more.

From the beginning of the research until so far, it have been 10 years of history about the effect of the tourism market heterogeneity on destination image and the tourists' behavior in the future. Many companies and professional research institutions focus on how to maintain a stable and loyal customer groups that bring great benefits for them. Customer loyalty is very important for any form of economic organization, of course, including the tourism industry. Through the summary and review on service industry marketing literature, we found that the current research focus is mainly on designing or developing an innovative model that can evaluate tourism destination image , and 
through which tourists' loyalty intention is analyzed. According to the survey of tourists from big cities in southern Spain, it is found that there is a significant difference between different tourists. In general, the tourists have the following aspects of demands: The first category is the largest segment of the market that is composed of individuals with moderately diverse needs ( $43.61 \%$ of the sample). The future behavior id affected by service quality, satisfaction and destination image. The second category is made up of the individuals who have a strong demand for change $(26.91 \%$ of the sample). Since their pursuit changes, the intention to revisit is low. The third category is the group who overall are lack of the pursuit of diversity (23.71\% of the sample). For them, satisfaction is the key variables whether they revisit or recommend. The fourth category has the smallest group (6.31\% of the sample), although there is a high demand for change, generally speaking, the intention of the recommendation is dependent on the quality of service.

Psychological image: The tourist destinations for accommodation, food quality and service attitude are highly needed, the above mentioned factors can make tourists feel calm and pleasant. High quality beach will make tourists feel worthwhile.

Mixed image: The health status of tourism destination, urbanization level, food and accessibility are necessarily needed. Researches on these components can make us have certain prospection ability to overall image of the tourism destination as well as the future behavior tendency of the consumers. After analyzed by structural equation model analysis method, the results show that the impact of psychological image and related functions on tourists is more important.

Some large-scale events or other large-scale activities play an important role in promoting the development of the local tourism, for example, the Olympic Games or the world Cup is able to attract a large number of tourists to come. The pulling effect of 2002 World Cup in Japan and South Korea on tourism industry is obvious including North Korea. The 2008 Beijing Olympic Games also created a large number of tourism revenue for the Chinese government. The South African tourism was infertile in the past, but the World Cup in 2010 brought abundant tourism income. This large sports festival can not only increase income of the local tourism and tourism staff, but also increase the local tourism employment and government revenue, and most importantly, it can also expand the publicity and reputation of relevant countries and tourism destination.

Perceived Value. Perceived value mainly refers to a variety of feelings they get from the consumers, so it's an overall evaluation on the product or service. In other words, it's a feeling or perception of a consumer whether the consumption is worth it. From the point of view of marketing, it is very important for perceived value to gain competitive advantage, and it is also one of the main measures for market subject to gain the competitive dominative position. Perceived value is a very important index to show tourists' satisfaction degree and behavioral intention measurement.

However, in this field tourism revisit intention and consumers' loyalty are usually predicted totally by consumers' satisfaction and (or) service quality. James $F$ had a deep understanding of perceived theory through the study of golf resort market. The construction of perceived value is divided into the value of the acquisition and the value of the transaction, both of which are related to the repurchase intention. The value of the acquisition: first, buying seasonal discount products make me feel good. Second, I am happy to learn that the seasonal discount for my golf holiday save me money. Third, seasonal discounts for me have gone beyond the pleasure of saving money. The value of the transaction: first, I think the value of golf resort holiday is worthy. Second, they are worth it. Third, after evaluating my golf resort holiday, I feel it is worthy. Forth, I feel I purchased inexpensive high-quality golf vacation.

\section{Some Suggestions on the Domestic Revisit Decision Behavior Study}

Based on the present research status of our country, basically the study on domestic revisit behavior is in reference to the basis of foreign research and study. However, both the depth of the study and the number of researchers or the number of research results have a large difference with foreign researches. And the research progress is relatively backward in recent years. According to the present research status of our country, combining with the relevant analysis of foreign researches, it's necessary to strengthen from the following aspects in order to make up for the insufficiency in 
the study of revisit decision-making behavior.: first, a detailed study on tourists' revisit behavior of tourism destination is needed, especially for the decision-making behavior, more efforts should be strengthened to investigate its multi-regional, different types and various channels so that research results are more scientific. Second, in order to make the analysis more comprehensive and scientific and has the guiding significance in practice, it's vital to use the modern economics, behavior science and even psychology to make a comprehensive analysis on tourists' revisit intention and related factors. Third, the research methods should be improved constantly. The quantitative analysis and empirical research methods ought to be used, the comprehensive advantages of current various research methods ought to be made full use of, and to the use of structure method and model method ought to be enhanced, which makes the research more modern scientific significance. Finally, by establishing a revisit rate evaluation structure and the corresponding evaluation index system of regional tourism destination, it's feasible to measure marketing performance and the development of the tourism, so that more data support is provided for marketing decision-making and marketing management.

\section{References}

[1] Y.L.Shi: The Construction and Dissemination of the Tourism Brand of Linyi under the Advantage of Cultural Resources [J]. Beijing: China Commerce and Trade, 2011(10).

[2] K.J.Wang: Study on Red Tourism Integration and Collaborative Development in Xiang-e-you-qian Regions [J]. Guiyang: Guizhou Ethnic Studies, 2006(4).

[3] J.P. Liu \& Y. Zou: The Development of Tourism Agriculture in Shaoshan Red Tourism Scenic Spot [J].Yiyang: Journal of Hunan City University, 2010 (4).

[4] Y.L.Shi: Research on the Rred Tourism Marketing Strategy Based on the Government Level [J]. Beijing: China Commerce and Trade, 2011(5).

[5] G.H. Chen and S.Y.Huang: An Empirical Study on the Influencing Factors of Tourist Revisit Decision Based on Internet Investigation [J]. Beijing: Tourism Tribune, 2008(11), pp.69-74.

[6] B.Wang, C.Y.Wu and Z.D Li: A Comparative Study of Initial and Repeat Visitors' Behavior [J]. Zhengzhou: Areal Research and Development, 2009(3), pp.68-71.

[7] Y. Yang: J.Zhang and N.X.Zhao, Study on the Tourist Experience and Revisit Intention Mechanism of Tourist Destination: Take Yixing for Example [J]. Beijing: Tourism Tribune, 2008(5), pp.42-48.

[8] G.H.Chen and S.Y.Huang: An Empirical Study on the Influencing Factors of Tourist Revisit Decision Based on Internet Investigation [J]. Beijing: Tourism Tribune, 2008(11).

[9] K.Bai and S.W.Guo: An Empirical Study on the Influence of Tourism Symbiosis Image to Tourists Revisit Intention and Word-of-mouth Effect -- Taking Xi'an Qujiang Tang Culture Theme Scenic Area as an Example [J]. Beijing: Tourism Tribune, 2010(1).

[10]X.H.Geng, X.Q. Wang and Q.S.Sun: Ecology Tour: Tourist Satisfaction and Revisiting Intention -- Based on the Investigation and Analysis of Suzhou Future Agriculture and Forestry World [J]. Kunming: Ecological Economy, 2010(6). 